\title{
ist \\ Technological risks, transgenic agriculture and alternatives
}

\author{
Pablo Rubén Mariconda
}

\begin{abstract}
is
ABSTRACT

After discussing the transformation of age-old agricultural practices that has been occurring since the mid nineteenth century, and its impact on the natural environment, I identify four features of technology that point to the ambiguity of the idea of "technological progress". These are linked to the intrinsic unpredictability (and uncertainty) of technological applications and have implications for evaluating technological risks. I then show that large scale technological applications and innovations - such as expanding the practice of smallpox inoculation in the second half of the eighteenth century - occur in states of 'technological exception'. In them, values are suspended and rules, limits and security norms are absent; and, in the face of risks, losses and harm to health and environment that are occasioned by technological applications introduced in the name of economical progress (development), normal social inhibitions become suspended in the name of furthering the values of capital and market. In addition, I show that maintaining technological exception has favored, on the one hand, the development by large corporations of antiscientific practices that threaten the moral integrity (ethos) of science by impeding the proper use of the scientific method for evaluating the consequences of using technologies that are protected by patents; and, on the other hand, under the cover of ignorance, continued deterioration of the environment that threatens the very survival of the human species.
\end{abstract}

KeYwords • Technology. Technological risk. Pluralism of Strategies. Transgenic Agriculture. Agroecology. Natural environment. Technical environment. Anti-science.

"Indeed the risk you run in purchasing knowledge is much greater than that in buying provisions."

$$
\text { Plato, Protagoras, 814, A }
$$

In this article I adopt the perspective of the model of the interaction between scientific activities and values (cf. Lacey \& Mariconda, in press). I consider particularly the application of scientific knowledge, so that my argument moves between the frontiers of science and technology. I discuss the complex relations and tensions between science and technology, attending particularly to what is called post-modern technoscience (cf. Mariconda, 2012), the predominance of practical and utilitarian interests in the politics of science, technology and innovation, and the hegemony of the values of control and (economic) progress or development (cf. Mariconda, 2006; Lacey, 2010). 
My argument is not complicit in what Putnam (cf. 2004, chapter 8) denounced as the "philosophers of science's evasion of values" throughout the twentieth century. Moreover, it rejects the view that values are expressions of personal and subjective preferences that are completely distinct from the objective facts (cf. Mariconda, 2006), and affirms with Dewey that "value is something that has to do with all of experience" (Dewey apud Putnam, 2004, p. 135). Taking values into account changes the axis of the relation between ethics and epistemology. It enables treating together the ethical problem of "the relation between personal freedom and the stable order" (Dewey apud Putnam, 2004, p. 178, note 2) and the general epistemological problem of the relations of the objective and the subjective in experience, with the consequence that it rejects confining ethics to the restricted sphere of subjectivity and so is able to recognize the proper role of ethics in scientific and technological activities. The evaluative perspective adopted is thus in line with the pragmatist outlook expressed in the formula: "the knowledge of facts presupposes the knowledge of values" (Putnam, 2004, p. 145), that abandons the empiricist dogma: "facts are objective and values are subjective and "never the twain shall meet" and accepts the challenge of considering scientific and technological practices from both epistemological and ethical perspectives.

In the light of this stronger connection between epistemology and ethics, I will address, on the one hand, epistemological questions about the unpredictability and uncertainty of (mainly big scale) technological applications, focusing on a major expression of commercially oriented technoscience, transgenic agriculture and its risks and impacts on health and environment (cf. Lacey, 2006, 2008) and, on the other hand, ethical questions related to the antiscientific behavior of large corporations. I will concentrate on the environmental question because the destiny of humanity is at stake in how it is dealt with (cf. Dupas, 2006, 2008).

\section{ThE TRANSFORMATIONS OF THE NATURAL ENVIRONMENT IN AGRIGULTURE}

The impacts of extensive mechanization and growing artificiality of the natural environment produced by technology can be seen in a striking way in the age-old practices of agriculture, which has been more and more transformed into a "technical environment", one increasingly mediated by technical objects and actions. To Friedmann, this transformation from a "natural environment" to a "technical environment" is generated by what he calls the "industrialization of agriculture", particularly with the large scale introduction of agricultural machines into the fields (furthered by the electrification and motorization), that facilitated the widespread growing of monocultures (cf. Friedmann, 1968, p. 9). 
This process of mechanization corresponds to the first stage of industrialization of the agricultural field and to the profound technical transformation of the agrarian natural environment, which furthers the tendency for technoscientific societies "to transform agriculture into an industry in accordance with Ford's definition of agriculture as 'an industry producing foods' and the modern mechanical developments as 'factories in the fields"' (1968, p. 118). Friedmann considered mainly the accompanying transformation of fields into cities that is an integral part of the all encompassing industrialization process that began in the middle of nineteenth century and continued throughout the twentieth century, and that was associated with a process of conurbation, ${ }^{\mathbf{1}}$ provoked by accelerated urbanization of peripheral zones of cities, where traditionally the plantations that supplied the cities were located.

Mechanization and urbanization of the field, however, constitutes only one aspect of the process of consolidating the technical environment - the establishment of a technical stage that would be maintained simultaneously with later kinds of development of the agricultural technical environment introduced from the 1960's on. The consolidation of this stage evidently occurred at the same time as the corresponding transformation of the agricultural activity of producing food and also, significantly, beginning in the second half of nineteenth century, of the discipline of Agricultural Science into a specialized area of engineering, whose earlier phases remained closely connected with working in the fields, but with later ones, following the advent of genetic engineering, important parts of traditional agronomical activity, such as the selection of seeds, would be transformed into laboratory and experimental specialties.

Meanwhile, two others stages would be added to this first stage of the transformation of agriculture into an industrial activity. (They correspond to the deepening of industrialization by means of further mechanization and automation). ${ }^{2}$ One, commonly called the "green revolution", involves the introduction of industrial products of chemical engineering, particularly, chemical agro-toxics and fertilizers, used intensively in

1 The term "conurbation" is attributed by Lewis Mumford (cf. 2008 [1961], p. 559, 645) to Patrick Geddes, who applied it, at the beginning of the twentieth century, to the urban agglomeration provoked by industrialization based on the use of coal and that "not infrequently propagates itself as a mass of relatively uniform density over (...) hundreds of square kilometers" (p. 559). Mumford extends the use of the term to apply it to the characteristic process of the twentieth century by which little separated villages and the suburbs of great cities become aggregated in an undifferentiated and shapeless urban mass in which there are no centers or an active urban life (cf. p. 632). He maintains that this generalized growing density and the propagation of the urban mass are no longer produced by "the original forces that created conurbation", the coal and the steam machine, but they "were supplanted by the net of electrical energy, by the electrified railroad, and latter by the automobile and highways" (p. 645); and that conurbation is the main force that "altered the overall equilibrium between urban population and agricultural population" (p. 632).

2 For a preliminary discussion on the repercussion of automation processes in the world of work, see Holzmann (2011), Ellul (1962), Merton (2013 [1947]). 
agricultural production with the aim of increasing economic returns rapidly. The other is that of intensive transgenic agriculture, following the development of biotechnologies informed by genetics, and molecular and synthetic biology, in particular the development of transgenic techniques which make possible the production of GMOs, conceived as biological machines. (Chemical engineering of the second stage is deepened by genetical engineering of the third; the development of specialization in Agricultural Science shifts from the field to the laboratory, from agronomy to genetics, and in the direction of experimental decontextualizing strategies).

Friedmann was preoccupied with a more encompassing characterization of technical environment that cannot be reduced to the impact of transformations in agriculture, and hence in the natural environment. He takes the "technical environment" to refer to "that environment developed in industrialized societies and communities since the beginning of the epoch of industrial revolutions" - i.e., from the end of eighteen century and first half of nineteenth century - in which "a network of complex techniques tending towards automatism comes more and more to entangle human beings" (Friedmann, 1968, p. 77). They include: productive techniques in industrial and in agricultural sectors; techniques of administration and distribution; techniques of consumption, including those that tend to transform domestic and family life; the various techniques of transport; and the techniques of communication. In addition, the "technical environment" brought with it a type of "psycho-sociological conditioning" (p. 81), in the sense that this environment provides or facilitates a certain type of psycho-social relation that tends to weaken social inhibitions towards the danger of accelerated environmental transformations provoked by technological applications.

It is important to keep in mind - especially in the discussion of the intensive introduction of biotechnologies in agriculture - that the distinction between natural and technical environments is neither absolute nor strict, since it makes no sense to treat human beings separately from their dialectical (mutually reinforcing) relations with their environments; thus, the expression "natural milieu" refers to an environment that "since pre-historical times [has been] a relatively technical environment" (Friedmann, 1968, p. 33; cf. Martins, 2012, p. 91-2). While domesticated plants and animals, for example, can be considered as artificial to a degree, modified by the "technical" process of domestication, they are clearly outcomes of the biological co-evolution of organisms and environment, just as human beings are. But clearly, the extended modification caused by technoscientific (anthropic) transformations of the environment trigger natural processes that fall well outside of the domains in which the technical capacity of control can be exercised, for example, the acceleration of climate changes that are threatening the survival of the human species. 
Finally, this presentation of Friedmann's ideas may be summarized using the incisive formulation of Jacques Ellul: "the technological order has become the new and specific environment in which human beings are required to exist, one which has supplanted the old one, that of nature" (Ellul, 1962, p. 394). I do not subscribe Ellul's thesis of the complete replacement of the natural by the technological environment, although I recognize that the natural environment in which we live is highly mediated by technology and technical devices. ${ }^{3}$ Consequently to say that our (post-modern) societies are technoscientific societies means that science and technology are subordinated to an economic order that evaluates and organizes them in terms of the likelihood of their contributing towards high productivity, profit and capital accumulation, or towards economic growth. Here, it is important to keep in mind that, while in current technoscientific societies it is the economic order, that is, the economical sphere of social activity, that serves as the vector that orders the technological system, in such a manner that different technical bodies (institutions) or subsystems gain priority according to their economical function (profit, capital concentration, market expansion etc.), in other civilizations there are other kinds of ordering vectors. In Ancient Egypt, for example, the vector is a transcendent metaphysical order, that of the possibility of an eternal life for which this earthly life is taken as a preparation, in such a way that it is the theological religious sphere that directs the hierarchy of technical systems designed to constitute the technological device that guarantees the passage from this earthly life to eternal life. The important concept which can be found in Ellul's conception is that of "technological order".4

\footnotetext{
3 To say that we live in a technoscientific society does not imply that nature has been completely supplanted or that the natural environment has disappeared, although natural tendencies are disappearing and being substituted or rivaled by artificial tendencies of the social technoscientific environment. On the contrary, the acceleration of climate changes, hurricanes, massive floods, prolonged droughts, and other natural catastrophes, to which human beings must adapt socially and organically, may be considered to be compensations of nature in response to the technical modifications imposed on the environment.

4 In general, Ellul uses the term "technique" in a wide sense that involves "not only the ways in which one influences things, but also the ways one influences persons" (Ellul, 1962, p. 394, note*), so that "technique" can be considered as the near equivalent of "technological order". But in some contexts, Ellul seems to use the term to designate particular procedures or technical solutions. In this article, I will use "technology" to refer to the system of techniques, this is, to the set of techniques and technical normalizations or regulations, and I will use the term "technique" when there is reference to uses and applications of particular techniques. Thus, genetic engineering is a particular technique pertaining to biotechnology, that is, to the set of molecular and genetically-based techniques.
} 


\section{SOME FEATURES OF TEGHNOLOGY LINKED WITH RISK APPRAISAL}

Before analyzing the impacts and risks that follow technoscientific transformations of agriculture and the highly artificial environment produced by it, in this section I will point to some features of technology that are especially important for the ethical dimension of technological appraisal, as indicated by Jacques Ellul (cf. 1962, p. 412-21) in the context of analyzing what can be called the "myth of technological progress". Ellul defends the thesis of the ambiguity of technological progress: "it cannot be maintained that technological progress is in itself either good or bad" (Ellul, 1962, p. 412), based on an argument in which he maintains that "contradictory elements are always indissolubly connected" (p. 412) to the development of technology. The thesis is manifested in four main features of the development of technology:

(1) All technological progress exacts a price;

(2) technique raises more problems that it solves;

(3) pernicious effects are inseparable from favorable effects; and

(4) every technique implies unforeseeable effects (Ellul, 1962, p. 412).

I will now analyze each of these features from the perspective of its role in evaluating technological applications in agriculture.

\subsection{Openness and Closedness of teghnological applications}

First, "all technological progress exacts a price" does not so much refer to a price in money or in intellectual effort, as signify that "when technological progress adds something with one hand, it inevitably subtracts something with the other" (p. 412-3). Ellul links this contradictory element to the fact that, "viewed objectively, technological progress produces values of indubitable merit while simultaneously destroying values no less important. Consequently, it cannot be maintained that there is absolute progress or absolute regress" (p. 4,13).

I will adapt Ellul's argument by saying that the development of technology is submitted to a kind of dialectics between openness and closedness of possibilities in technoscientific applications, ${ }^{5}$ that is, between the new possibilities opened by new 5 My argument is freely adapted from (without pretend to be an exposition of) the anthropologist Gérard Chazal (2007, p. 67-8). It is also related with what Feenberg (2009, p. 75-80) calls the "intertwined hierarchy of technology and society", in which there is a process of reciprocal construction between technology and society. Truly the two aspects - dialectics of closedness and openness of possibilities and intertwined hierarchy of technology and society - are both cases of an universal invariance which consists in the final analysis in the interactive relation between organisms and environment or, to put it anthropologically, in the relation of humans and the environment. 
technological development, and those that at the same time are closed - so that in extensive technological applications generally, accompanying the realization of new possibilities, there is a reduction of possible courses of actions and consequently of choice. ${ }^{6}$ This means that decisions about implementing a technical innovation should take into account (or be guided by) the dialectics between openness and closedness in a context that makes comparison with possible alternative applications. Only by subjecting each technological project to comparative analysis or examination can one identify clearly the novel possibilities that may be realized and those that may be destroyed.

Consider, for instance, transgenic agriculture, clearly a product of technoscience. It represents the implementation at large industrial scale of very specific technological possibilities such as the application of transgenic techniques aiming to produce seeds resistant, for example, to certain chemical herbicides. Hence, GMOs enrich and expand the possibilities opened up by the Green Revolution that led, in the 1960s, to the chemical industrialization of agriculture with the large scale use of agrotoxics and chemical fertilizers, and to the increasing artificiality of technical environment in the fields and generally in agriculture. However, in virtue of the intensified use of agrotoxics in large plantations of GMOs, soil and water pollution increased and accelerated, insect and amphibian diversity, as well as the variety of seeds of the species under cultivation, were reduced in function of contamination by transgenic genes, and reduction of native species. These consequences add up to a dramatic reduction of natural assets (which become ever more scarce with the advance of technical environment). They also undermine the possibility of developing alternative technologies, such as agroecology, that explore less destructive and more harmonious possibilities, and that are more dependent on natural environmental assets, for example, the existence of fertile, non-depleted, unpolluted, recoverable soils.

\subsection{TEGHNOLOGICAL PROBLEMS AND THE ROLE OF ALTERNATIVES IN THEIR SOLUTION}

The second feature is that "technique raises more problems than it solves" (Ellul, 1962, p. $412,4,14,-7)$. It involves that technology develops "by solving a certain number of problems, and by raising others" (p. 414), which cannot be resolved by the same technique that gave origin to them, or that "there is never one technique, which solves one problem" (p. 415, italics in the original). This means that applying technology to solve problems is, on the one hand, a systematic issue that depends upon the set (or network) of techniques that compose the whole system or the "technological order" and

6 In certain sense the most powerful instances of the effectiveness of human will in the world are also the ones that narrows the space for the exercise of human will - a paradox that puts into question the limits of technical control of the world. 
that can explore the technical possibilities made available by the system. On the other hand, a technological solution is always a technical solution to a single problem considered by itself, so that the solution is decontextualized, partial, and very specialized, and when used at large scale in the technical environment produces a series of effects at various of its levels that require other techniques to be dealt with. This ambiguity clearly points once again to the necessity of taking into account the range of possible alternative techniques permitted by the technological system of a certain epoch.

All this can be seen as part of "the vast proliferation and diffusion of the technological way of life, diffusion that is as much vertical and intensive in what is called "colonization of the living world' (Lebenswelt), as horizontal and extensive on the planetary scale: the technological monoculture" (Martins, 2012, p. 160). Thus, the predominance of GMOs monocultures in the domain of agriculture is not surprising, it being an exemplary case of technological colonization of the food system, that through extensive and accelerated technical transformation of the environment, brings it about that unpredictable and undesirable effects of the generalized application of highly specialized techniques become consummated facts. These consummated facts are then used to put constraints on ex post facto regulation, which again is always a technique, in virtue of the technological environment in which they are inserted, and which consolidates in the social order often irreversible consequences-including irreparable losses, for example, connected with plant diversity and soil fertility - for the stock of natural assets. There is thus a constant societal process of assimilation of the undesirable consequences by means of which society adapts, through technical and juridical regulation, to the environmental transformations so that efforts to introduce social and ethical restrictions of undesirable or even bad technological consequences are inhibited; this serves as a technological device to maintain the process of "colonization of the living world".

Evidently the above argument contains the tacit supposition that "only technology can resolve the problems occasioned by technology", because every technical solution is introduced into the technological order or system, which is a network of social spheres (economic, educational, law), of areas (urban, sanitary, environmental), of levels (local, regional, global), of scientific disciplines, and of technical specialties derived from experimental knowledge that these disciplines make available. The technological system is therefore an open system that makes available a broad set of particular techniques applicable in the areas, and on which the successful applicability of techniques depends on the natural and artificial assets of the present configuration of technological environment. In this sense, even an alternative solution, which is environmentally favorable and economically sustainable, is still a technical solution, and cannot be otherwise. However, although the technological system is an open system, it 
does not escape being subject to the economic order; that is, the various technical possibilities are arranged in an hierarchy and favored depending on their contribution to economic development and growth.

But to accept the supposition that there are only technical solutions to problems generated by technology does not oblige one to adhere to technological determinism, that is, that there is only one type of technique available that could deal with the problems generated by particular technical solutions, or in other words, by technical solutions for problems defined inside artificially restricted contexts, that are experimentally controllable (hence, rigorously decontextualized), and so produced within closed technical sets of solutions. A technological version of the argument for the best possible world is insinuated here, one that Martins calls ironically the "theorem of Panglossian existence": "there are always technological solutions for the problems created by technologies (especially biomedical and ecological problems)" (Martins, 2012, p. 161). However, to consider this proposition as a theorem of technological determinism depends on the degree of assent given to the suppositions:

(1) that the solution presented is the best possible solution, in fact, the only one which is appropriate (and efficient);

(2) that "there are no alternative technologies that are appropriate, intermediate, and with more favorable outcomes" (Martins, 2012, p. 160).

Both suppositions face great difficulties. Regarding the first, technical solutions are inevitably incomplete, since they are solutions for problems defined within artificially restricted (rigorously decontextualized) contexts. When they are applied on a large scale in the highly artificial environment of the technological order, they engender an inevitable "residue of new social technical problems due to the incompleteness connected with interactions and limitations" of the closed technical sets and of "their unpredictable secondary effects" (cf. Martins, 2012, p. 162). The latter are the effects of the large scale causal propagation through highly artificial technological environments of specialized technical solutions, that is, solutions whose technical efficacy was narrowly considered within the boundaries of the closed technical set to which they pertain, and so they generate other technical problems that have to be treated by other technical sets:

(...) this thesis of the inextricable and unceasing chaining of problems, solutions, and new technological problems (...) [implies that] new technological or technical-social problems proliferate more rapidly than solutions, and that the set of residual problems become more difficult than previous ones due to factors such 
as the dynamic of technology, growing complexity [of technological system], increasing costs and decreasing resources, exigencies for greater control, and the inertia of social institutions (Martins, 2012, p. 162).

Furthermore, the tacit presupposition that there are no alternatives expresses only a determinist understanding of "technical efficacy". This can be questioned from the perspective of the difficulties related to the first supposition and also because it reflects the hegemony granted in scientific institutions to decontextualizing (experimental and reductionist) strategies. Hence, it favors technical solutions based on experimental research of controlled causal mechanisms in the restricted environment of the laboratory because these solutions involve the increase of control of specific artificial and natural processes of closed technical sets that compose our technological environment. Decontextualizing strategies are not the only scientific strategies that may orient efficient technical applications, however; and they are incapable of solving the residual problems that propagate through other spheres of the highly artificial technological environment.

The solution of residual (technical/artificial and natural) problems, that are produced by negative effects or unexpected accidental consequences of specialized technical solutions, can only be treated by open technical sets that make use of contextsensitive strategies or even of a plurality of strategies, for appraising the efficacy of a solution requires taking into account the full range of both intended and residual effects of a technical application. Then, when making decisions about applying large scale technical solutions, it becomes possible to consider alternative technical solutions that balance economic with social and environmental efficacy.

But while the technological version of the Panglosian theorem of existence secretes technological determinism, the market version of this theorem secretes economic determinism. Following the neoliberal version of Panglosian theorem of existence:

Every problem caused by markets can be solved in a timely manner by more and better markets (whether these problems are economic, social or ecological), and not by non market behavioral patterns and models" (Martins, 2012, p. 163).

The argument for economic determinism depends on the same kind of suppositions that are used in the argument for technological determinism, and whose difficulties I have just presented. Regardless of its value as a determinist principle, however, the Panglosian theorem represents an attempt to close the cycle - technological and economic - of the efficacy of technical solutions, excluding the possibility of alternative technical solutions. Thus, in the economic version, the negative residual ef- 
fects of a technical application are considered "negative technological externalities or non commodities (...), the environmental disasters such as the famous "tragedy of the commons' can be solved by market solutions and only by market solutions" (Martins, 2012 , p. 163). This means that residual effects of technical-chemical solutions in agriculture, such as air and water pollution, should receive a technical solution compatible with the economic efficacy, which limits technical efficacy to the closed agro-biochemical technical set that is exactly the technical set that cannot be developed without causing air, water or food pollution. These latter remain as residual problems without an economically viable technical solution. Then, these problems tend to receive a market solution: either insurance that pays monetary indemnities to those affected by the irreversible consequences caused by the solutions of agro-bio-chemical techniques, or transforming the question of pollution into an economic market, as in the case of carbon credits.

Again, all this is well illustrated by the agricultural technoscientific solution introduced to resolve the technological problem of producing food in chemical polluted areas, by means of the accelerated artificial production of seeds and the expansion of intensive monoculture, that generates a chain of effects such as increase of chemical pollution in the environment, reduction of the variety of cultivars, decrease of insect populations (or mutations that generate "super-insects"), disappearance of pollinators (bees and others), degrading of ever more extensive areas of arable soil (and the consequent necessity of expanding the frontiers of farmlands and the probable destruction of the Amazon Forest), creation of conditions favorable to the appearance of "superweeds" etc. Furthermore, transgenic agriculture contributes to put pressure of society's capacity to deal with health problems such as the increase of breathing problems in children and aged people, the continuing process of displacing people from rural to urban zones - problems that can only be solved by other techniques available in the technological order, or that are linked to another conception of technical efficacy.

\subsection{THE INSEPARABILITY OF BENEFIGIAL AND HARMFUL EFFEGTS OF TEGHNOLOGY}

The third feature concerns the effects and consequences of applying technologies to the solution of problems. It can be expressed by "the thesis of the inseparability of beneficial and harmful effects of using technologies", which has an immediate consequence at the ethical level. This thesis rejects outright the idea, which is basic and central to much common moral thinking, that technology is intrinsically neutral, and that whether it is used for beneficial or harmful ends depends on decisions made by its users. This idea generates (in the light of the inseparability thesis) the illusion that there need not be harmful consequences or that they can be cancelled by "good uses". 
Consider the example of nuclear technology. Whether it is used for peaceful or military ends, it is implicated in harm (for example, nuclear waste that must be kept under constant surveillance since it is highly contaminating for a long period) that cannot be ignored on the ground that it is intrinsically connected with the beneficial effects of the uses of nuclear technology; it is impossible to generate energy for the good of people without generating very harmful toxic waste. Another equally obvious example is that of the use of genetically modified seeds, which cannot be used without causing loss of diversity (variety) of the crop species planted.

This feature is particularly relevant to decision making about possibly implementing dangerously polluting chemical technologies. Moreover, the thesis of the inseparability of beneficial and harmful effects can lead to critical questioning of what is commonly called "standard risk analysis". It leads to recognizing that both the terminology employed - "risk" instead of "harmful consequences" -, and the consequent classification of risks as "potential" or "real" or "effective", involve the presupposition that technology is neutral, for it produces manifest benefits, and only potentially occasions risks (and harmful consequences). This presupposition is manifest once again when evidently harmful effects such as the deaths of many people (as in the case of the leaking of gas in Bopal chemical industries) or the demonstrated loss of environmental diversity are called "real risks", implying the supposed intrinsically beneficial character of the technology, relegating the harmful consequences to the level of error or bad use. This takes issue with the utilitarian (clearly economic) interpretation of the concept of "risk" promoted by the large corporations, and the implicit reduction of all value to economic value (profit or loss). Standard risk analysis is fundamentally an organizational or management (technical) tool that serves for calculating the probability of economical loss in connection with the application of a particular technical innovation, and of the corresponding costs of unpredicted residual effects of the large scale use of products developed under experimental controlled conditions. In fact, it is part of a technological device of power that, as we shall see in section 3 , is exercised so as to favor (make possible), always in the name of economical progress or development, social reluctance to address the negative consequences of technology (cf. Fressoz, 2012; Agamben, 2007).

\subsection{UNPREDICTABILITY AND UNGERTAINTY OF TEGHNOLOGIGAL APPLICATIONS}

The fourth feature of the ambiguity of technological progress is expressed in an universal mode by Ellul: "all technological progress contains unforeseeable effects" (1962, p. 419). When new technical means and new technological solutions are discovered, they are applicable to precisely delimited technical spheres (facts) in such a way that 
certain results (effects) are expected and obtained. However, in virtue of the highly artificial environmental and the (open) interactions of the expected effect with the totality of effects of the system "there are always secondary effects that were not anticipated, and that in the first stage of the technical progress in question could not in principle have been anticipated" (p. 419-20). This unpredictability could be avoided only if the complete experimental exploration of all possibilities permitted by the technological system at every moment were possible, and obviously it is not.

Note, in the first place, that this points to a strong link between predictability and experimental control. Unpredictability means that we are dealing with variables that were not taken into account in the experimental design which leads to a particular technical development. In second place, since the aim of technology is to control technically the events that occur in the world, complete predictability, that is, the possibility of conducting experiments concerning all objects and dimensions of the technological system (the "complete possibility of experimenting in every sphere") remains as an ideal, which maintains, on the one hand, relations of mutual reinforcement with the value of control, but imposes, on the other hand, the recognition of the limits (boundaries), sometimes very narrow, to which technical solutions are subjected.

Ellul illustrates the thesis of technological unpredictability by means of examples of unpredictable effects in three technological spheres: pharmaceuticals and chemistry; urbanism; agriculture. (This will give us the opportunity of returning to the reflection on the transformations of natural into a technical environment.)

Concerning pharmaceutical and chemical technologies, Ellul discusses three cases: aspirin, DDT and thalidomide. Aspirin has remarkable effects connected with eliminating headaches, but its prolonged ingestion has the undesirable collateral effect of increasing susceptibility to severe hemorrhages. DDT, the first agrotoxic used extensively and intensively, was considered in 1945 to be "a prodigiously successful means for the destruction of all kinds of vermin and insects" (Ellul, 1962, p. 420) and absolutely innocuous to human beings. But, when consequently it was intensively applied on the surface of the planet, it turned out to have the unpredicted secondary effect of causing anemia in animals and in humans. Regarding thalidomide, Ellul just mentions its terrible genetic and teratological effects, and reiterates that "identical problems [that is, of producing harmful collateral effects] are potentially raised by all chemicals consumed by animals or men" (p. 420). The upshot of this discussion is the following characterization of secondary (collateral) effect:

secondary [collateral] effects: effects which are essentially unpredictable and only revealed after the technique in question has been applied on a grand scale (...) (Ellul, 1962, p. 420). 
This characterization of collateral effects is relevant for the exercise of the Precautionary Principle and points again to the necessity for more scientific research on the collateral effects of the continued use of drugs and of toxic substances on animal and human health, in order to anticipate those effects that are unpredictable in the short term. (Obviously, the health of plants, animals, and humans are linked by the food chain, and polluted air and water undermine environmental health.)

Another kind of technological unpredictability is found in the urban dimension of the technical environment, more directly linked with psycho-sociological effects on the behavior of the inhabitants of large cities, because in the urban planning we are very specially "confronted with the effect of the technological environment on human beings" (Ellul, 1962 p. 420). In large cities, feelings and sensations of isolation, loneliness, absence of human contacts, physical and mental stress, fear of violence, etc, are common. Large scale urban projects, like those of Le Corbusier, that were based on the diagnosis that these problems originate in the fact that "big cities dwellers do not know one another", and that, in order to favor human contact and redirect the psycho-sociological effects, involved the construction of "large blocks of dwellings where people could meet one another as they would in small cities, with everything (grocer, baker, butcher) included in the block so that people would get to know one another and a community would come into being (...)" (Le Corbusier apud Ellul, 1962, p. 420). However, the psycho-sociological result of constructing the large housing blocks, instead of being a return to an idealized community life inspired in villages, was the opposite of that predicted, for the problems of solitude and isolation became aggravated by the significant increase of violence that erupted in these urban agglomerations. In fact the construction of large housing and residential blocks ended up being integrated into a technological device aiming to solve two basic urban problems: housing and locomotion. Many programs of slum ("favela"; "villa-miseria") removal in Latin America followed this model of construction of big agglomerates of housing blocks. This solution also produced part of the process of suburbanization on the peripheries of large cities, and the destruction of natural environments as well as the reduction of productive farmlands (cf. Mumford, 2008 [1961], cap. 16-17).

The other part of the process of urbanizing rural areas was a consequence of the overwhelming predominance of automobile; and, in American countries, the predominance of transport moved by burning fossils fuels led to constructing a network that inter-linked cities based on roads and freeways that cut through rural zones, many of which are dedicated to food production. It led also to an urban network of avenues, tunnels, bridges, viaducts and parking lots that clearly prioritizes the individual automobile (cf. Mumford, 2008 [1961], cap. 17). This huge technological system of transport enabled the urbanization of the rural areas increasingly distant from the suburbs 
of large cities by means of developing urban projects - promoted by the construction business and directed towards the middle class - that create gated communities with controls on the entry and exit of people, and that often transform farms and fertile and arable lands into urban condominiums (cf. Mumford, 2008 [1961], cap. 16). From the psycho-social point of view, this kind of model of community, far from allowing a life closer to nature, supposedly calmer, more balanced, and favorable to rest and leisure, ends up producing unexpected difficulties, and becoming a source of physical and mental stress. On the one hand, people living in these artificially created communities tend to generate a psychological environment of suspicion and censorship, in which "people are perpetually under the eyes and the surveillance of their neighbors" (Ellul, 1962 , p. 421). On the other hand, the growth of rural urbanization leads rapidly to traffic jams at the entrance points of the great cities, requiring more and more time to travel between one's distant residence and work place in the city. This example shows how urban planning solutions, broadly technical ones from the economic, managerial and engineering point of view, can produce unexpected and even psycho-social consequences that are contrary to those expected.

Intensive conventional agriculture, "the massive cultivation of certain plants like corn and cotton" (p. 421), practiced in the United States, Brazil, Russia, and Argentina among other countries, provides Ellul's third example of unpredicted effects of large scale technological applications. From the technological point of view, the extensive plantations (monocultures) of corn and cotton have represented economic progress because they produced an enormous increase in productivity. Deforestation also resulted in economic progress, doubly profitable because of commercialization of woods from the destroyed forest and opening up new areas for cultivation and hence productivity. However, it was not anticipated (predicted)

that corn and cotton are plants which not only impoverish the soil, but even annihilate it by the twofold action of removing certain natural elements and destroying the relation between humus and the soil particles. Both are destroyed by the roots of cotton and corn to the extent that, after 30 or 4,0 years of cultivation of these agricultural products, the soil is transformed into a veritable dust bowl. A strong wind need only to pass over it to reduce it to bare rock (Ellul, 1962, p. 4,21$)$.

Intensive agriculture has similarities with the first example of pharmaceutical and chemical products. Once again there is an unpredictable (in the short term) collateral effect that becomes manifest only when the technological solution is applied at large scale over a long period of time, in this case, thirty or forty years. What the second 
and third examples have in common is that they are part of the same process of technical transformation of the rural environment that results in the continuing decrease of fertile areas that could be used for production of food at small scale in the peripheral areas of large cities. In addition, in the huge productive areas of the interiors of American countries, the disaster of green revolution, which in part is pertinent to Ellul's examples of corn and cotton, is transformed by transgenic agriculture into a catastrophe for the environment and health. The large scale applications of chemical, genetic and biochemical solutions greatly increase the negative collateral effects on the environment, what the economists call "environmental externalities", obliging an increase of social tolerance to risks and harmful consequences. There is an acceptation that the environmental externalities of large scale technological applications, such as reduced water resources, chemical pollution and soil infertility, the residual cumulative effects of continuous ingestion of GMOs etc. are the price that we have to pay for progress, modernization, development and, more recently, innovation.

There is a powerful compensatory mechanism (that removes social inhibitions) that generates continuous adaptation between the transformations of the technological environment and the social practices that unfold in it. This mechanism is a technical device that has the components: standard risk analysis; insurance against damage and risks, and regulation of techniques, that is, the introduction of technical codes and legislation about the limits of use and application of certain techniques. The function of this procedure is to engender acceptance that, although the techniques may have dangerous or harmful effects, their benefits justify having tolerance to the risks they occasion.?

\section{TEGHNOLOGIGAL RISKS AND THE STATE OF TEGHNOLOGICAL EXGEPTION}

There is a precise anthropological sense in which the complementary relation between humans and the environment in which they live is what defines humanity. The human is its environment; and the environment in which humans beings live is the measure of human intervention in nature; and the degree of artificiality of the environment is in the final analysis the measurable expression of our separation from nature. The further the transformation of the natural into a technical and artificial environment proceeds, the more we subject ourselves to the unpredictable (in the short term) consequences of technology and to the uncertainty of our partial technical solutions, and, as

${ }_{7}$ There is no space here to deal with the economic consequences of technological unpredictability and, in particular, of the economical aversion to uncertainty (cf. Martins, 2012, cap. 5, p. 180-8). 
in the case of agriculture where biotechnological and chemical solutions are applied at large scale, we run the risk of environmental and health catastrophes and losing natural assets to such an extent that we even endanger the survival of the human species. Technoscientific agriculture confronts us with "the violence of danger that eliminates all protective zones and all modern differentiations" (Beck, 2010 [1986], p. 7). I will deal with this notion of "risk" that is used to characterize society in the present state of development of technology.

In a simple way, "risk" is synonymous to "danger", in other words, risk expresses the possibility of danger, that is, it expresses the high probability of the occurrence of an inconvenient effect or a fatality, whose occurrence cannot be controlled by the same particular technical solution which make possible that particular technical action or application. Risk also applies to the unpredictable (in the short term) consequences and to the residual effects (produced by the effect of causal propagation through the technological environment) of technical solutions applied at large scale.

"Risk" is an anthropocentric notion, from which follows its ethical dimension, for it would not be risk without human implication, without some kind of technical action (cf. Bourg, 2007, p. 123) on the environment, without having repercussion on what is to be an human in such an environment. This is why in the dimension of human social organization the notion of "risk" acquires an important juridical sense, according to which in insurance contracts, risk is understood as an incident (an economic loss, a physical or material harm) which demands indemnity. Risk, in the juridical sense, refers then to the responsibility or the duty related to the loss or harm caused by a technical action that produces such a risk situation. In the economic sense, however, a risk is evaluated by the economic (cost/benefit) standard risk analysis, and it can be defined as the association between an eventuality (probability of economic profit in an technological endeavor or application) and a vulnerability (probability of harm to people, individual goods or society; harms that evidently will result in losses to be covered be insurance or paid by monetary indemnities) (cf. Bourg, 2007; Dusek, 2009, p. 89-97).

The philology of the word "risk" is clarifying. The term appears in the West in the middle of twelfth century, when Pisa and Genoese merchants borrowed from "arabic the word 'rizq' ('the part that God attributes to each men') to designate in their contacts the losses and profits linked to uncertain events" (Fressoz, 2012, p. 27), that is, to increase the profits and diminish the losses (or insured part of these) in function of danger. Throughout the fifteenth century the term "risk" was in regular use among Portuguese and Spanish navigators in connection with financing the technical and economic adventure represented by great feats of navigation and by the colonization of America. This means that the insurance system linked to economic risk, as well as the 
accounting system registering receipts and payments, were part of mercantile capitalism, long before risk was incorporated in the insurance system of industrial capitalism during the chemical revolution of eighteenth century and its technical application on a large scale during the first industrial revolution after the French Revolution.

Maybe it was Jean-Jacques Rousseau who first used the term in the sense of the expression "technological risk" referring not only to the economic sense of insurance, but applying it to the urban planning (technical) conception of the cities. Differing from Voltaire's revolt against the "violence of nature" in the earthquake that destroyed Lisbon in 1755, Rousseau maintained that the responsibility was in greater part human, attributing the catastrophe to the risk to which inhabitants of Lisbon had exposed themselves for "having grouped twenty thousand dwellings of six or seven floors" (Rousseau apud Bourg, 2007, p. 123-4); and many people had died looking for their belongings, an attitude that reveals the ignorance of the danger to which they were exposed.

During the historical process of constitution of the technological system - which is a fundamental part of the process of scientific-technological rationalization of modern societies that has continued from the mid eighteenth century until today - there was consolidated a social perception of risk, molded in a technical-economic conception of the same risk. This conception is based in the standard risk analysis, which is an instrument of the economic rationalization of profits and losses being part of a technological device - in major part mathematical, constituted by probability, statistics, game theory and rational decision theory - that enables the direct technological dangers and its eventual negative social and environmental consequences to be absorbed by the market. This is done by the financial and actuarial processes of insurance that have accompanied industrialization since the first Industrial Revolution until the chemical and biotechnological industrialization of present agribusiness.

If we look at the great technological interventions that marked the transformation of the natural environment into the present technological order, an environment more populated by technical objects and even artificial living beings, we can detect the mechanism by which the negative consequences and residual effects are assimilated, and come to be considered as acceptable (natural, inevitable) integral parts of the environment. This technological device makes viable a process of social adaptation to technology and to the risks, harms to health and environment that it occasions, that are incorporated by means of what Fressoz calls "the ontological form of the modern neutralization of inhibition", taken in the sense of "the set of descriptions that aim to adjust the world to the technological imperative" (Fressoz, 2012, p. 286) of modernization and economic development. And, in fact, the neutralization of social inhibition seems to be more effective when it is established "in the immediacy of the relation between the world and the techniques" (p. 286), because in this manner it 
obtains the aim to "weaken the technological impact and neutralize the critical sense of the accidents, in order to capture, orient and align the perceptions and the behaviors in the sense of technique" (p. 287). There is then a constant process of social neutralizing of inhibition by which risks and accidents, intrinsically linked with technical solutions and applications, are incorporated as parts of certain technical sets of the technological order, and in this manner after a long period of regulation - which can never be completed - become normal, controllable within certain parameters, and so are neutralized in the technological order; at the same time social inhibitions concerning risks are weakened in view of modernization, technological progress and economic development.

Furthermore, the process of gradual construction of the technological system that is composed by the network of technical devices embodies a historical systemic invariant, namely, the exceptionality of the social, health and environmental situation created by every new large scale application of technical solutions - a state of technological exception (that in itself does not require explanation, and that is tacitly taken for granted), in which values and "the traditional norms that rule health, property, environments, imputations of harms, and responsibilities" (Fressoz, 2012, p. 288) are suspended. In this exceptional state, certain matters concerning artificial beings, new technical devices of control, and the inevitability of residual or even bad effects of technological solutions are able to become consummated facts. While the state of technological exception endures, incessantly more and more of such consummated facts about environmental, social and health risks are created, and they have impact in juridical debates and ex post factum technical regulation of its limits. The state of technological exception corresponds, then, very significantly to the maintenance of a state of suspension of rules, laws and established order, to a suspension of social and ethical values and particularly, as we shall see in section 4 , to suspension of the values of scientific ethos, thus to adopting an antiscientific posture. It authorizes the execution of an open-ended process of experimentation that always involves increasing the technical component of the environment, and that produces effects and consequences which are very far from being predicted, controlled or avoided.

The juridical manner of solving the state of technological exception consists in closing the technological cycle by means of regulations on (for example) the new artificial living beings, and on the procedures, dangers, accidents or harms caused by them. Beginning with recognizing the consummated facts generated by technology, technical and juridical regulation "redefines the stuff of the world, the beings that compose it, and its regularities, redefining equally the technical forms" (p. 290). However, recognizing a consummated technical fact imposes on science the task of describing and explaining it with the intent of absorbing the exception, setting its limits, and neutral- 
izing its effects in the technological order. Therefore, science and also technique give rise to a procedure of expertise - that supposes a specialized knowledge not only about the disputed matter but also in the process of regulation - by which technology ends up imposing a technical regulation on society, instead of society establishing the social, sanitary and environmental limits of technology. Observe that the process of regulation occurs for the most part in a state of exception and, consequently, of suspension of habitual normative practices, and that it concludes with the normalization of the exception (cf. Fressoz, 2012, p. 289). So, the closed cycle of technical and juridical regulations - which goes from the state of technological exception, in which are generated the technological consummated facts, to the conclusion of technical and juridical regulation - gradually prepares the process of weakening social inhibitions concerning risks, that is, the adjustment of society to the exception by turning it into the "normal", based on the imperative of technological progress and economical development.

This cycle - state- of-technological-exception/consummated-facts/regulationcan be seen as an invariant component of the historical development that brought about the gradual implementation, from the $175^{\circ}$ s on, of the technological order, the introduction of the scientific mentality in the productive system, and gradually in more sectors of society. Modernization and technological progress - that correspond to the advance of scientific rationality and of the bureaucratic order in society - is found in the hygienist movement of prevention of smallpox that agitated France, England and the United States from the middle of eighteenth century, and that is undoubtedly the first large scale application (in public health) of a medical technique derived from the medical study of infectious deceases. The movement began with the discovery that the inoculation of the pus from the pustule of smallpox could make a person immune to the disease; and led, in the course of the campaign to combat smallpox, following an internal technical development, to the discovery of the vaccine and to the technical development of its production, conservation and use in inoculation. In this very large scale experiment with human populations, conducted sometimes far away from controllable conditions, epidemics broke out and, during a long period of time until the stabilization of the vaccination technology, the smallpox inoculation produced many death and, among those immunized, many collateral effects, such as blindness and (most commonly) deformations in the inoculated limb. This huge experiment conducted on the civil population generated revolts and resistance that lasted until the technique was stabilized, its efficacy was proven, and it was regulated as an acceptable (even desirable) practice of public health that could be imposed on the population by the force of the law. In this case, one can see a clear neutralization of inhibitions in the face of dangers and harm occasioned by these sanitary campaigns, in the name of the modernization of society and medical and health related progress (cf. Fressoz, 2012, cap. 1-2). 
One can find the same cycle at the very beginning of the first Industrial Revolution in the process of chemical industrialization, with the production of artificial soda financed by the French bourgeois after the Revolution of 1789. Following the discovery of the chemical synthesis of soda and the technique for artificially producing it - due to the extraordinary development of Chemistry during what is called the Chemical Revolution of the eighteenth century - the establishment of factories (of all sizes) that produced soda accelerated, in Paris, Lyon and other French cities and their suburbs. These factories generated environmental disorder in their surroundings, with the air intensely polluted by toxic acid gases that corroded walls of buildings, clothes hanging on clotheslines destroyed, and serious breathing problems caused for those who lived close to the factories, while in the fields there were great losses of crops. The state of technological exception that lasted four decades from 1780 to 1810 was resolved partly with the improvement of the chemical process of soda production that aimed to eliminate the emission of acid gases, and this involved elaborating technical norms of security; and partly by the creation of a system for insuring the industrial capital invested in chemical production, so that the insurance system would be improved parallel to the advance of technical security regulation. Until the end of the state of technological exception there continued to be intense environmental pollution in the cities and fields around the first French industries, and there was intense social and juridical debate about prohibiting this kind of factory and about indemnities for material, environmental and health harms caused by the chemical production of soda (cf. Fressoz, 2012, cap. 3-4).

Finally, the same cycle-state-of-technological-exception/consummated-facts/ regulation - was present during the whole nineteenth century with the development of the steam engine and with the transformation it brought about in the means of industrial production (for example in the mechanization and automation of the textile industry) and in the means of terrestrial (trains and railroads), fluvial and naval (steam ships) transport. The whole process of implanting steam technology occurred in a state of technological exception. This had to do, on the one hand, with the accidents produced by steam engines, such as the explosions, the avoidance of which eventually was to depend on the technical development of boilers with internal controls of the pressure of the steam inside of them, and of mechanisms of refrigeration, in order to be avoided; and, on the other hand, with the huge environmental transformation caused by the railroad with the beginning of the production of energy by burning fossil combustibles - first with coal and then coke (cf. Mumford, 2008 [1961], cap. 15; Fressoz, 2012 , cap. 5). Here also there was a long process of regulation, maintained partly by the technical process of improving engine security and partly by insurance for accidents and indemnities to victims. The combustion engine, the automobile and the highway 
transport deepened the environmental consequences of burning fossil combustibles, and extended, with respect to their environmental consequences, the state of technological exception until our own days.

It is not surprising that the process of industrialization of agriculture consolidated in the 1920 s with the mechanization of the fields and the advance of monocultures, and continued in the 1960s with the Green Revolution and the advance of the use of chemicals in agriculture and, from the 1990 s on, with transgenic agriculture, has occurred in a state of technological exception which has endured for almost a century, and maintained a lasting process of regulation of negative environmental and health consequences of large technological applications in agriculture. The state of technological exception seems to be thus intrinsic to the very idea of technological innovation. In Brazil it serves to neutralize social inhibitions in the face of negative environmental and humanitarian consequences, as in the case of hydroelectric plants being constructed in the north of the country, and of health and environmental consequences, as in the case of agribusiness, always in accordance with the imperative of modernization/development and economic growth. In fact, it permits the exercise of the naked power, in the Hobbesian sense, because it is the power of the stronger exercised regardless of any social pact in a state of affairs in which the usual and accepted values and rules are suspended.

\section{Teghnological EXGePtion AND ANTI-SGienGe PRAGTiGeS}

The state of technological exception that, as we have seen, is necessary for the development of technical innovation practiced by the large pharmaceutical and chemical corporations permits these corporations to develop a political and rhetorical practice that aims to retard the regulatory process. This practice contributes to prolonging the state of technological exception - and it is antiscientific. Its unscientific character shows itself in three ways: (1) by impeding scientific research on the health and environmental effects of pharmaceutical drugs and chemical substances; (2) by deliberately propagating fraud and ignorance; (3) by continuing to apply and to expand the chemical biotechnological innovations even after scientific verification that they cause harm and after their prohibition in certain countries (mainly in Europe).

\subsection{THE ATTACK ON SCIENTIFIC IMPARTIALITY}

The antiscientific attitude is manifested in the fact that pharmaceutical and chemical corporations normally refuse to furnish the data of the tests on the collateral effects of 
their products carried out in their own laboratories, sometimes even to laboratories connected with the official regulatory agencies. The corporations justify this by alleging that openness about their data would undermine the protections that their patents grant them to maintain secret the constitution of their products (drugs and seeds); and following this allegation, legal prohibitions and restrictions have been put into place on the scientific research that may be conducted on, for example, the collateral, residual and cumulative effects and harms caused by large scale uses of agrotoxics, and on the effects on health of the prolonged and continued ingestion of GMOs (cf. Mariconda \& Ramos, 2003).

Impeding access to the information about data related to technical solutions, and prohibiting independent research on its collateral effects obstruct the exercise of science, are incompatible with the scientific method. They prevent the repetition of experiments and comparing data obtained in the corporations' laboratories with those obtained in other laboratories that may involve, for example, variations of the initial conditions of dosage and combinations of chemical substances. These impediments and prohibitions also obstruct experimental research oriented towards the technical improvement of security norms being a part of the regulatory process. Where they apply to research on the collateral, residual and unpredictable effects of specialized technological applications that, as we have seen, generate problems whose solutions can only be found in other scientific disciplines and in other techniques, it is evident that there is external interference - in this case, by economic interests - in determining the objects of scientific research and in applying the scientific method. Thus, we find undermined the autonomy of scientific institutions to investigate, using the standard procedures of the scientific method, the efficacy and the limits of technological applications.

Finally, these impediments and prohibitions introduced in order to maintain secrecy represent a threat to scientific impartiality, the constitutive value of scientific method, the one that stipulates that scientific evaluation should be based only on cognitive criteria (cognitive values, such as empirical adequacy, explanatory power, predictive power, precision, simplicity and comprehensiveness) and the full array of relevant empirical data. The value of impartiality is, thus, intimately linked with procedures for the scientific certification of hypotheses and theories and confirmation of results, based on methods and procedures universally agreed upon that guarantee the objectivity in principle of the knowledge and understanding obtained of phenomena of the world (Lacey \& Mariconda, 2012). Because of the secrecy and privacy that they involve, patents stand opposed to the open and public practices needed to ensure scientific impartiality: "the institutional conception of science as part of the public domain is linked with the imperative for communication of findings. Secrecy is the antithesis of this norm; full and open communication its enactment" (Merton, 2013, 
p. 192; 1957, p. 557). Thus, to impede scientific research based on patent rights amounts to imposing a scientific moratorium, because effectively "the definition of technology as "private property' in a capitalistic economy" (Merton, 2013, p. 193; 1957, p. 558) is incompatible with the value of communalism, for example, with the conception that the contribution of individual people to scientific knowledge are part of the shared stock (capital) of scientific knowledge. Furthermore, obstructing scientific scrutiny of data and research on the collateral, residual, unpredictable, uncertain effects (risks) etc creates obstacles for developing technical (and also legal) regulations. This antiscientific behavior is aimed at maintaining the state of technological exception.

\subsection{The PRODUCTION OF IGNORANCE}

The vast agricultural (biotechnological) experiment that is being promoted by agribusiness with the diffusion of monocultures of GMOs - a clear expression of "experimenting in every sphere" (see section 2.4, above) - , generates (unpredictable or undesirable) social, psychological, environmental and ecological externalities (cf. Martins, 2012, p.110). The change of jargon is intentional, in order to better deal with the scientific-technological system insofar as it is structured economically, for agribusiness corporations consider the multiple social, etc consequences of large scale technological applications as externalities, that is, as undesirable effects for which the revenue of crops and its extraordinary contribution to economic development serve as sufficient compensation. In the light of the economic criteria of capital and market, health and environmental consequences and harms are simply the price that society has to pay for technological progress and economic development.

In order to challenge this, since the effects on health of ingesting GMO food products are unpredictable in the short term and, being residual and cumulative, will only be manifested after 30 or 4.0 years, scientific research needs to be pursued intensely in order to make a more methodical empirical appraisal of the chain of health and environmental effects triggered by this agricultural experiment. In this way, the problems of acting without precaution, and of implementing chemical biotechnology in the shortest possible time, become apparent. The harm caused by industrial antiscientific practices also becomes evident. These antiscientific practices impede the scientific appraisal of the consequences triggered by the technology, and hence risk analysis itself. This appraisal requires that first the residual and cumulative effects that are propagated through the technological order and its highly artificial environment should be investigated; and then the social, health and environmental consequences that follow from these effects and the possible solutions to any problems that they may cause and, at the same time, to evaluate the development of alternative 
technological solutions to the production of food, such as agroecology, which is potentially highly productive economically.

It is in the context characteristic of the state of technological exception that arises the second antiscientific practice (with serious ethical consequences) of the deliberate production of error, or "fabricated ignorance" (Martins, 2012, p. 73). Ignorance has always stood between justice and utility, and claiming to be ignorant of the consequences of practiced acts has always served as an alibi in courts of justice, because where there is genuine ignorance there is not the ethical intention to perform an evil act. It is important, however, to distinguish two kinds of ignorance.

On the one hand, there is "genuine ignorance", that is, that ignorance produced by technological development (progress) which generates risks and uncertainties that cannot be eliminated, "not only because we are ignorant of the causal mechanism, but because no degree of knowledge would be able to eliminate the uncertainties which follow from the interactions between the new social-technique systems and the biosphere" (Martins, 2012, p. 73). Genuine ignorance is evidently linked to another of the values that are components of the scientific ethos in Merton's sense: organized skepticism, to the demand of detailed critical scrutiny of scientific contributions. This is a consequence of recognizing the conjectural/hypothetical character of science and leads to recognizing the fallibility of scientific knowledge; and effectively skepticism appears as a fundamental characteristic of Popper's conception that scientific hypothesis (theories) should be submitted to severe and rigorous empirical tests in a context of comparison with alternative hypothesis or theories (cf. Popper, 1965, cap. 5). For Merton, organized skepticism is intimately related to the other constitutive values of scientific ethos: universality, disinterest, originality, communalism, and it is conceived as " both a methodological and an institutional mandate" that prescribes "the suspension of judgment until "the facts are at hand" and involves "the detached scrutiny of beliefs in terms of empirical and logical criteria" (cf. Merton, 2013, p. 197; 1957, p. 560 ).

On the other hand, in the last quarter of the twentieth century, "fabricated ignorance" has been spreading in "market economies in consolidated democracies". It consists of

campaigns to produce ignorance (...), doubts, uncertainties concerning well founded scientific thesis, with spurious arguments, distortions of results, data from badly conducted research, testimonials presented by specialists in courts to raise doubts about sound results of scientific investigations (Martins, 2012, p. 173 , note 18$)$. 
The campaigns of production of ignorance have occurred repeatedly from the end of the 1970s - and they have become a common practice of the tobacco industries (Proctor, 1995), ${ }^{\mathbf{8}}$ petroleum companies and more recently chemical-biotechnological corporations. They aim to induce ignorance by means of generating doubts on themes or results about which there is an extensive scientific consensus. 9 Thus, despite the fact that it had been well established scientifically that there are strong statistical correlations between smoking tobacco and occurrence of lung cancer, the tobacco industry was able to postpone regulation of tobacco by means of an organized program aimed at putting into doubt and discredit scientific evidence about this connection.

One of the significant aims of the program for the production of ignorance is "to keep the controversy alive" (Leite, 2014, p. 181). It is based on a combined antiscientific strategy of (1) discrediting (producing false beliefs about) inconvenient scientific data, by producing other more favorable data (under different initial conditions, with different statistical methods etc.); and (2) defaming the scientific reputations of those researchers who present scientific evidence verifying the undesirable consequences of large scale application of particular techniques promoted by multinational corporations. The evident aim of "to keep the controversy alive" is to impede regulation, prohibitions and restrictions, or to postpone them as long as possible, while maintaining the state of technological exception. The fact that, in 125 cases brought against tobacco industry between 1954 and 1979 there was not a single conviction (cf. Leite, 2014, p. 182), proves the advantage for the corporations of maintaining the state of technological exception. It also shows that, despite all the impediments and restrictions that, from the 1990 s on, were imposed by the courts on the tobacco industry and smokers, regulations were not able to be introduced, for example, concerning the composition of the substances in cigarettes. This is an evident sign that regulatory bodies have incorporated tobacco activities into the technological order - by limiting but not essentially modifying them, and that social inhibitions against using tobacco have to a certain extent been neutralized in the service of economic interests.

The same antiscientific practice reappears in more recent campaigns of the petroleum industry (from 1995 on) that aim to attack the Intergovernmental Panel on Climate Change (IPCC) (cf. Leite, 2014, p. 180-1), by producing doubts about the anthropic effects of climate change, in particular, the contribution of fossils fuels to climate change. However, recent discussions about the birth of a new geographical era - the Anthropocene - in the evolution of the Earth may be an index or an indication

8 In this book Proctor introduced agnotology as a discipline concerned with the production of ignorance; a discipline complementary to epistemology, that is, to the study of knowledge production.

9 I can't treat here of the role of propaganda and media in the production of biased conceptions, and how this media device is used in generating fabricated doubt (cf. Ellul, 2014, [1965]). 
that technological environment has attained planetary scale, and that technology now may represent an important factor having impact on the climate dynamic of the Earth. Here, in view of the failure of all international attempts until now to set out limits to the emission of greenhouse gases produced by burning fossils fuels, one can clearly see that the state of exception is persisting.

The same kind of deliberate fabrication of ignorance occurs in connection with transgenic agriculture by the six companies - Monsanto (United States), Syngenta (Suisse), Dupont (United States), Basf (Germany), Bayer (Germany) and Dow (United States) (cf. Thuswohl, 2013, online) - that dominate the production of GMOs. They use a double strategy for the deliberate production of error. It involves, on the one hand, systematically conducting research aiming to challenge scientific data on the harm to environment and health caused by the extensive use of agrochemicals in agriculture and of on-going ingestion of GMOs; and, on the other hand, promoting campaigns to defame individual researchers, and even in some cases taking legal action, citing their intellectual property rights under patents, to prevent scientific research on the health and environmental effects of using transgenic plants and consuming their products.

The dissemination of fabricated ignorance deploys rhetorical skepticism against scientific organized skepticism. Instead of employing doubt to promote knowledge, it employs it to discredit scientific knowledge in order to disseminate ignorance. The skeptical procedure of doubting is then used with the deliberate aim of deceiving or defrauding. In contrast, the conjectural (hypothetical) and fallible character of scientific knowledge - that recognizes that scientific solutions are always subject to change (in view of knowing more, understanding better, and becoming less ignorant) in the light of rigorous empirical and conceptual critique and more severe tests based on scientific method - is linked with organized skepticism, one of the component values of the scientific ethos (cf. Merton, 2013, chap. 7) that is one of the outstanding institutional features of science. Applying the scientific method thus presupposes the acceptance of scientific ethos - a set of values of which the value of impartiality is part - and the practice of the virtues of honesty and sincerity that accompany the scientific use of method (practiced along with the values of organized skepticism), and respect for the moral imperatives of not lying about empirical data and evidences, of not using fraudulent research data, of not plagiarizing, etc. Thus, it presupposes certain precise moral commitments that are denied by the procedure of production of ignorance.

Significantly, creating doubt about scientific certifications, discrediting the legitimacy of security norms indicated by this certification, and postponing the introduction of regulations, maintains the state of technological exception and expands the range of health and environmental consumed facts. The aim is clear; the means employed to obtain it is immoral. 


\subsection{IgNORANGE AND ETHIGS}

The third antiscientific practice consists in de-legitimating scientific decisions, ignoring warnings about risks and harms to health and environmental occasioned by their technical applications, in order to keep the application in place where the state of technological exception can be maintained. Operating here, the consequence of transgression of the scientific ethos and of the immorality of the employed means, is a sort of disguising of knowledge or feigning of ignorance. However, to continue the use of agrochemicals, chemical fertilizers, and transgenic seeds locally in certain countries when this is already prohibited based on scientific certification of their extensive genetic, teratological, mutational effects etc. - for example, the herbicide 2,4-D (cf. Neumeister, 2014) - means that the corporations cannot claim ignorance of the consequences of their decisions of applying technical solutions with such known potential of consequences. Proposals to prohibit planting transgenic seeds and using agrochemicals that are based on scientific reports that recognize the danger of these effects, and also their contribution to the present ecological crises. Thus, to continue applying technical solutions, where there is compelling scientific certification that there are harmful health and environment consequences and residual effects, is to bring these harms about deliberately; this can be considered a criminal action. Furthermore, keeping in mind the co-evolution of human beings and their environment (cf. beginning of section 3 above), and the dependence of human survival on a sustainable environment, actions that bring about these harms, since they are deliberate, may be considered to be crimes against humanity: they modify the environment in such a way as to extend to future generations the harms caused by extensive application of agrochemicals, thereby decreasing the chances of survival of the human species.

This brings us back to the beginning of the article, to the problem of ethical responsibility for using such technological practices. Ethical responsibility demands an understanding of the "relation between personal freedom and the stable order" in view of the values adopted and of the objective knowledge at hand, both of which - values and knowledge - compose all of experience. Looked at in this way, actions of corporations and industries that are decided by a directorate, composed of individuals, cannot be treated ethically as the actions of a collective juridical personality. Ethical responsibility demands individual (personal) freedom of decision. So from the point of view of ethical responsibility, that is, of the relation between personal freedom and the social order, members of a directorate are, first and foremost, individuals - presidents, directors, scientists, technicians, engineers - to be held individually responsible for the consequences of decisions in which they are implicated. 
Finally, the whole antiscientific program - undermining scientific impartiality, deliberately fabricating ignorance, and continuing to use technologies whose harmful consequences have been confirmed by sound scientific research - deviates from the scientific ethos, i.e., from the complex of values that has animated modern science. All of its components are expressions of the antiscientific attitude that animates the programs of technoscience and technological innovation of the neoliberal economy, and in line with the neoliberal conception of the minimum state and its program of deregulation. Deviating from the scientific ethos in this way has the effect of annulling the impact of ethics and thus undermining the most basic source of sensitivity to the requirements for humanity survival.

Acknowledgements. An earlier version of this article was presented at the 18th International Conference of the Society for Philosophy and Technology (SPT-2013), Lisbon, Portugal, July 6, 2013. I thank Hugh Lacey for his valuable help in discussing the main points of this article and for helping to put it in right English language. This article is part of the Thematic Project "Origins and significance of technoscience: on relations among science, technology and society", supported by Fapesp.

\section{Pablo Rubén Mariconda}

Department of Philosophy, Faculty of Philosophy, Letters, and Human Sciences, Institute for Advanced Studies, University of São Paulo, Brazil. ariconda@usp.br

\section{REFERENGES}

Agamben, G. Qu'est-ce qu'un dispositif? Paris: Payot \& Ravages, 2007.

Bachelard, G. Le rationalisme appliqué. Paris: Vrin, 1949.

BEck, U. Sociedade de risco: rumo a uma outra modernidade. São Paulo: Editora 34, 2010 [1986].

Bourg, D. Qu'est-ce qu'un risque environnemental? In: Kermisch, C. \& Ноттогs, G. (Ed.). Techniques et philosophies des risques. Paris: Vrin, 2007. p. 123-38.

Cairns, H. \& Cairns, H. (Ed.). Plato: the collected dialogues. Princeton: Princeton University Press, 1961. Cattani, A. D. \& Holzmann, L. (Org.). Dicionário de trabalho e tecnologia. Porto Alegre: Zouk, 2011.

Chazal, G. Dimension anthropologique du risque technique. In: Кевмisch, G. \& Ноттоis, G. (Ed.). Techniques et philosophies des risques. Paris: Vrin, 2007. p. 57-69.

Dupas, G. O mito do progresso ou progresso como ideologia. São Paulo: Editora Unesp, 2006. . O impasse ambiental e a lógica do capital. In: (Org.). Meio ambiente e crescimento econômico: tensões estruturais. São Paulo: Editora Unesp, 2008. p. 21-89. (Org.). Meio ambiente e crescimento econômico: tensões estruturais. São Paulo: Editora Unesp, 2008.

Dusek, V. Filosofia da tecnologia. Tradução L. C. Borges. São Paulo: Loyola, 2009.

ElLul, J. The technological order. Technology and Culture, 3, 4, p. 394-4,21, 1962. Propagandas. Tradução M. S. Pereira. Lisboa: Antígona, 2014 [1965]. 
Feenberg, A. Ciencia, tecnología y democracia: distinciones y conexiones. Scientiae Studia, 7, 1, p. 63 81, 2009.

Fressoz, J. B. L'apocalypse joyeuse. Une histoire du risque technologique. Paris: Seuil, 2012.

Friedmann, G. 7 estudos sobre o homem e a técnica. São Paulo: Difel, 1968.

Holzmann, L. Automação. In: Cattani, A. D. \& Holzmann, L. (Org.). Dicionário de trabalho e tecnologia. Porto Alegre: Zouk, 2011. p. 56-9.

KeYnes, J. M.A treatise on probability. New York: Harper, 1962 [1921].

Кевмisch, G. \& Ноттоis, G. (Ed.). Techniques et philosophies des risques. Paris: Vrin, 2007.

LACEY, H. A controvérsia sobre os transgênicos. Aparecida/São Paulo: Ideias \& Letras, 2006.

Crescimento econômico, meio ambiente e sustentabilidade social: a responsabilidade dos cientistas e a questão dos transgênicos. In: Dupas, G. (Org.). Meio ambiente e crescimento econômico: tensões estruturais. São Paulo: Editora Unesp, 2008. p. 91-13o.

Valores e atividade científica 2. São Paulo: Associação Filosófica Scientiae Studia/Editora 34, 2010.

LACEY, H. \& MARICONDA, P. R. The eagle and the starlings: Galileo's argument for the autonomy of science. How pertinent is it today? Studies in History and Philosophy of Science, 43, p. 122-31, 2012.

.\& __. O modelo da interação entre as atividades científicas e os valores. ScientiaeStudia, 12, 4. In press.

Leite, J. G. Controvérsias científicas ou negação da ciência? A agnotologia e a ciência do clima. Scientiae Studia, 12, 1, p. 179-89, 2014.

Martins, H. Experimentum humanum. Civilização tecnológica e condição humana. Belo Horizonte: Fino Traço, 2012.

MARICONDA, P. R. O controle da natureza e as origens da dicotomia entre fato e valor. Scientiae Studia, 4, 3, $45^{3-72,2006 .}$

. Get ready for technoscience: the constant burden of evaluation and domination. Review of Javier Echeverría “La revolución tecnocientífica”. Scientiae Studia, 10, Special Issue, p. 151-62, 2012.

Mariconda, P. R. \& Ramos, M. De C. Transgênicos e ética: a ameaça à imparcialidade científica. Scientiae Studia, 1, 2, p. 245-61, 2003.

Merton, R. K. Social theory and social structure. Glencoe: The Free Press, 1957.

Science and the democratic social structure. In: Social theory and social structure. Glencoe:

The Free Press, 1957 p. 550-61.

.Ensaios de sociologia da ciência. São Paulo: Associação Filosófica Scientiae Studia/Editora 34, 2013.

A máquina, o trabalhador e o engenheiro. In: Ensaios de sociologia da ciência. São Paulo: Associação Filosófica Scientiae Studia/Editora 34, 2013 [1947]. p. 233-51.

Mumford, L. A cidade na história: suas origens, transformações e perspectivas. São Paulo: Martins Fontes, $2008[1961]$.

Neumeister, L. The risks of the herbicide 2,4-D. Testbiotech/GeneWatch UK/ Pesticides Action Network (PAN) Europe. January 2014. Available at: <http://www.genewatch.org/uploads/fo3c6d66agb3545 357384,83c1c3d4.9e4/Risks_of_herbicide_2_4_D.pdf >.Accessed: 20 Sept. 2014.

Platão. Protagoras. Tradução W. K. C. Guthrie. In: Cairns, H. \& Cairnss, H. (Ed.). Plato: the collected dialogues. Princeton: Princeton University Press, 1961. p. 308-52.

Popper, K. R. Logic of scientific discovery. New York: Harper \& Row, 1965.

Рвостов, R. N. Cancer wars: how politics shapes what we know and don't know about cancer. New York, 1995.

Proctor, R. N. \& Schiebinger, L. (Ed.). Agnotology-the making and unmaking of ignorance. Palo Alto, 2008.

Putnam, H. The collapse of the fact/value dichotomy and other essays. Cambridge/London: Harvard University Press, 2004.

Tнияwонц, M. Grupo de seis empresas controla mercado global de transgênicos. Repórter Brasil, 2013. Available at: <http://reporterbrasil.org.br/2013/11/grup o-de-seis-empresas-controla-mercadoglobal-de-transgenicos-2/>. Accessed: 20 Aug. 2014. 